\section{Parental Perceptions of Oral Health Status in Preschool Children and Associated Factors}

\author{
Monalisa Cesarino Gomes ${ }^{1}$, Marayza Alves Clementino ${ }^{1}$, Tassia Cristina de \\ Almeida Pinto-Sarmento ${ }^{1}$, Edja Maria Melo de Brito Costa ${ }^{1}$, Carolina Castro \\ Martins², Ana Flávia Granville-Garcia', Saul Martins Paiva ${ }^{2}$
}

'Post-graduation Program in Dentistry, UEPB - Universidade Estadual da Paraiba, Campina Grande, PB, Brazil 2Department of Pediatric Dentistry and Orthodontic, UFMG Universidade Federal de Minas Gerais, Belo Horizonte, MG, Brazil

Correspondence: Dra. Ana Flávia Granville-Garcia, Rua Capitão João Alves de Lira, 1325/410 58428800 Campina Grande, PB, Brasil. Tel: +55 83 3315-3326. e-mail: anaflaviagg@hotmail.com

\begin{abstract}
The aim of the present study was to evaluate parental perceptions of oral health status in preschool children. A cross-sectional study was carried with 843 Brazilian children between 3 and 5 years of age. Parents/guardians answered a self-administered questionnaire on the health of their children and sociodemographic data. Parental perceptions of their child's oral health were determined by the responses to the following question: "How would you describe your child's oral health?" The Brazilian version of the Early Childhood Oral Health Impact Scale (B-ECOHIS) was answered by parents/guardians and used to measure the impact of oral health-related quality of life $(\mathrm{OHROoL})$ on preschool children and their families. Three examiners performed oral exams on the children $(K=0.85-0.90)$. Descriptive analytical statistics were carried out, followed by logistic regression for complex samples $(\alpha=5 \%)$. The following variables were significantly associated with parental perceptions of children's oral health: parental perception of general health as poor $(\mathrm{OR}=18.25 ; 95 \% \mathrm{Cl}$ : 3.36-98.96), negative impact on family's $\mathrm{OHROoL}(\mathrm{OR}=13.82 ; 95 \% \mathrm{Cl}$ : 4.27-44.72), child aged five years $(\mathrm{OR}=7.40 ; 95 \% \mathrm{Cl}: 1.49-36.63)$ and the interaction between history of toothache and dental caries (OR=10.02; 95\% Cl: 1.17-85.61). Thus, parental perceptions of oral health are influenced only by clinical conditions with symptoms, such as dental caries with toothache. Other oral conditions, such as malocclusion or traumatic dental injury, were not associated with parental perceptions of their child's oral health.
\end{abstract}

Key Words: oral health, preschool child, parents.

\section{Introduction}

Preschool children often have oral health problems, such as dental caries $(1,2)$, traumatic dental injury (TDI) $(3,4)$ and malocclusion (5), especially in deprived (1) and rural areas (2) with lower socioeconomic conditions and less access to health assistance. The reduction in the occurrence of these conditions requires public health programs with educational/preventive strategies and the offer of dental care. However, the success of such programs depends on awareness of parents/guardians regarding their child's oral health status (6). Parental perceptions are particularly important in this phase due to the inability of preschool children to verbalize their emotions (7).

Indeed, adequate oral health care and visits to the dentist are associated with parental perceptions regarding children's oral health (8). Parents/guardians play the central role in ensuring their child's wellbeing and are the main decision makers with regard to the child's health care (7).

A number of factors have been described as predictors of parental perceptions regarding children's oral health, such as the child's age, household income, ethnicity and oral health problems $(7,9,10)$. However, some studies did not evaluate the effect of oral health-related quality of life $(\mathrm{OHROoL})$ on parental perceptions regarding oral health
$(7,10)$. Such an analysis can demonstrate what aspects influence perceptions of health - whether the OHROoL of children (symptoms, functional, psychological and social limitations) or the OHROoL of their families (financial impact and parental guilt). A recent paper reports that the negative impact exerted on OHROOL among children and their families may influence parental perceptions, but did not involve a representative sample of the population (9). Other representative studies have evaluated the association between parental perceptions of their child's oral health and perceptions of OHROoL. However, such studies addressed the perceptions of oral health as independent variables and did not address their associated factors $(11,12)$. Thus, representative studies with a randomly selected sample involving preschool children are needed to obtain external validity and allow the data to be extrapolated to other populations.

The evaluation of the determinants of parental perceptions regarding the oral health of children can assist in assessing treatment needs, prioritizing care as well as evaluating the outcomes of treatment strategies and initiatives in health care (10). However, there is a lack of preschool-based representative studies in the literature that determine the influence of oral health problems on 
parental perceptions regarding children's oral health. Thus, the aim of the present study was to evaluate determinants of parents'/guardians' perceptions regarding the oral health status of their children.

\section{Material and Methods}

\section{Sample Characteristics}

A cross-sectional study was carried out with male and female preschool children aged 3 to 5 years enrolled at public and private preschools in the city of Campina Grande, Brazil. Campina Grande has 22,400 children aged three to five years old, 12,705 of whom are enrolled in preschools. The participants were selected from the total population of children in this age group that attended preschools $(n=12,705)$, corresponding $6.41 \%$ of this population, and therefore constitute a representative sample of preschool children in Campina Grande. Campina Grande (population: 386,000 inhabitants) is divided into six administrative districts; mean monthly income per capita is US $\$ 110$ and the Human Development Index is 0.72 (13). This study was conducted from October 2011 to April 2012.

The sample size was calculated with a $4 \%$ margin of error, a 95\% confidence level and a 50.0\% prevalence rate of parental perceptions of their children's oral health. A correction factor of 1.2 was applied to compensate for the design effect. The minimum sample size was estimated at 720 schoolchildren. A further $20 \%$ was added to compensate for possible losses, giving a total sample of 864 schoolchildren. A 50\% prevalence rate was considered to increase the power, as this value gives the largest sample regardless of the actual prevalence (14). The percentage distribution of three-to-five-year-old preschool children in each of the six administrative districts was calculated from information provided by the Campina Grande Municipal Board of Education on children in this age group enrolled at preschools. To ensure representativeness, the sample was stratified according to administrative district and type of institution (two-phase sampling method). Preschools were randomly selected from each administrative district in the first phase. Among the 127 public preschools and 122 private preschools in Campina Grande, 18 public and 15 private preschools (total: 33 schools) were randomly selected to ensure proportionally in the enrollments. Next, children were randomly selected from each preschool while maintaining the proportional enrollments.

\section{Eligibility Criteria}

The following inclusion criteria were used: either sex, age three to five years, enrolment in preschool and accompaniment by a parent/guardian fluent in Brazilian Portuguese. The exclusion criteria were systemic disease, handicap or learning disability (according to the reports of parents/guardians) and the absence of the four maxillary incisors due to dental caries or physiological exfoliation, which could compromise the clinical diagnosis of malocclusion and TDI.

\section{Training and Calibration Exercise}

The calibration exercise consisted of two steps (training and clinical). The training step involved a discussion of the criteria for the diagnosis of TDI, malocclusion and dental caries as well as an analysis of photographs. A specialist in pediatric dentistry (gold standard in this theoretical framework) coordinated this step, instructing three general dentists on how to perform the examinations. The clinical step was carried out at a randomly selected preschool that was not part of the main sample. Each dentist examined 50 previously selected children between three to five years of age. Inter-examiner agreement was tested by comparing each examiner with the gold standard ( $K=0.85$ to 0.90 ). A seven-day interval was respected between clinical examinations for the determination of intra-examiner agreement ( $K=0.85$ to 0.90$)$. Data analysis involved the calculation of Cohen's Kappa coefficient on a tooth-bytooth basis. As the Kappa coefficients were very good (15), the examiners were considered capable of carrying out the epidemiological study.

\section{Pilot Study}

A pilot study was conducted to test the methodology and understanding of the questionnaires. The children in the pilot study $(n=40)$ were not included in the main sample. As there were no misunderstandings regarding the questionnaires or methodology, no changes to the data collection process were deemed necessary.

\section{Application of Questionnaires}

Parents/guardians were previously contacted to attend a meeting at the preschools, at which they received clarifications regarding the objectives of the study. Parents/ guardians who agreed to participate signed a statement of informed consent and were then instructed to answer a questionnaire addressing perceptions of health and socio-demographic data and the Brazilian version of the Early Childhood Oral Health Impact Scale (B-ECOHIS). All questionnaires were filled out by the parents/guardians and returned at the end of the meeting.

Parental perceptions of their child's oral health were determined by the responses to the following question: "How would you describe your child's overall oral health?" The response options were 1) very good, 2) good, 3) fair, 4) poor and 5) very poor. The proportion of responses was very $\operatorname{good}(19.9 \%), \operatorname{good}(46.5 \%)$, fair (25.9\%), poor (5.6\%) and very poor $(2.1 \%)$. Since the proportions of poor and very 
poor answers were low, the answers were dichotomized as good (responses of good and very good) and poor (responses of fair, poor and very poor) for statistical purposes.

A history of toothache and parental perceptions regarding the child's overall health were also investigated and a questionnaire addressing the following sociodemographic data was administered: child's sex and age, mother's schooling (years of study), number of residents in the home, relationship to siblings (only child, youngest child, oldest child and middle child), type of preschool (public or private) and household income (classified based on the Brazilian minimum monthly salary, which was equal to US\$312.50), $\leq 1$ minimum salary or $>1$ minimum salary).

The parents/guardians answered the B-ECOHIS for the evaluation of the impact of oral health on quality of life of preschool children and their families. The ECOHIS is a proxy measure of children's OHROoL for which parents/ guardians are the secondary respondents, as it is believed that very young children do not have sufficient cognitive skills to evaluate their own quality of life. This method has been validated in the literature (16). The B-ECOHIS is divided into two sections (Child Impact and Family Impact), totaling 13 items distributed among six domains $\vec{s}$ (symptoms, function, psychology, social interaction/selfimage, parental distress and family function), all answered by parents/guardians, regardless of whether the respondent was the child's mother, father or other guardian. Oral impact on the children was assessed using nine questions (reported pain, had difficulty drinking hot or cold beverages, had difficulty eating some foods, had difficulty pronouncing words, missed preschool or day care, had trouble sleeping, been irritable or frustrated, avoided smiling or laughing and avoided talking). Family impact caused by the child's oral problems was assessed using four items (been upset, felt guilty, taken time off work and financial impact). Each question has six response options: $0=$ never; $1=$ hardly ever; $2=$ sometimes; $3=$ often; $4=$ very often; $5=$ don't know. The response options are dichotomized for each section ("don't know" responses are not counted). Impact on the OHRQoL of the children and their families was recorded when at least one response of "sometimes" was recorded, whereas absence of impact was recorded when all responses were "never" or "hardly ever". The Brazilian Portuguese version of this questionnaire has been validated and used in previous studies (16).

\section{Clinical Oral Exam}

Clinical examinations were performed on the children after the questionnaires and signed statements of informed consent were returned to the researchers. The exams were carried out by three dentists who had undergone the training and calibration exercises. Prior to the exam, the children brushed their teeth under the supervision of the examiner, using a toothbrush, toothpaste and dental floss for the removal of bacterial plaque to facilitate the diagnosis. The exams were performed at the preschools. The child remained seated in front of the examiner, who performed the exam with the aid of a portable head lamp (Petzl Zoom head lamp, Petzl America, Clearfield, UT, USA). The dentists used individual protection equipment, sterile mouth mirrors (PRISMA ${ }^{\oplus}$, São Paulo, SP, Brazil), sterile Williams probes (OMS-621, Trinity ${ }^{\oplus}$, Campo Mourão, PA, Brazil) and gauze to dry the teeth.

Dental caries was diagnosed using the International Caries Detection and Assessment System (ICDAS II) (17), which ranges in score from 0 (absence of caries) to 6 . The ICDAS II was chosen due to the fact that this measure allows the assessment of initial carious lesions (white spots) on the enamel and active lesions in the dentin, contrarily to the World Health Organization criteria, which only evaluate cavited lesions. However, due to the epidemiological nature of the present study, code 1 was not used, as drying of the teeth was performed with gauze rather than compressed air. Code 2 denotes a white spot. Codes 3 and higher denote different degrees of cavitation (17). For statistical purposes, dental caries was dichotomized as absent (code 0 for all teeth) or present (code $\geq 2$ ). Caries on the maxillary incisors was recorded when at least one upper incisor received a code $\geq 2$, regardless of the lesions on the posterior teeth.

The classification proposed by Andreasen et al. (18) was used for the clinical diagnosis of TDI: enamel fracture, enamel + dentin fracture, complicated crown fracture, extrusive luxation, lateral luxation, intrusive luxation and avulsion. A visual inspection of tooth discoloration was also performed. TDI was recorded in the presence of any type of TDI or discoloration. Malocclusion was recorded in the presence of at least one of the following conditions: increased overbite ( $>2 \mathrm{~mm})$, increased overjet $(>2 \mathrm{~mm})$, anterior open bite, anterior crossbite and posterior crossbite $(19,20)$. Following the exam, a fluoride varnish was applied to the teeth of all children and those with carious lesions or other dental needs were sent for treatment.

\section{Statistical Analysis}

Descriptive statistics were performed for the characterization of the sample. The frequency distribution of the data was determined. The dependent variable was parental perception of oral health (dichotomized as good/ poor). Logistic regression considering the design effect in sampling weights for complex samples was conducted for each dependent variable $(p<0.05)$. Independent variables with a $p$-value $<0.20$ were incorporated into the multiple logistic regression model using the backward stepwise procedure. The interaction factor was tested for history of 
toothache and dental caries. Statistical analysis was carried out using the Statistical Package for Social Sciences (SPSS for Windows, version 18.0, SPSS Inc, Chicago, IL, USA).

\section{Ethical Considerations}

This study received approval from the Human Research Ethics Committee of the UEPB -Universidade Estadual Paraiba (Brazil) under process number 00460133000-11 in compliance with Resolution 196/96 of the Brazilian National Health Council.

\section{Results}

A total of 843 pairs of children and their parents/ guardians participated in the present study, corresponding to $97.56 \%$ of the total determined by the sample calculation. The loss of 21 children was due to incomplete questionnaires or "don't know" responses on the B-ECOHIS ( $n=11)$, absence of the child on the days scheduled for the exams $(n=4)$ and a lack of cooperation during the exam $(n=6)$.

In relation the socio-demographic data of the sample, similar distributions were found regarding child's sex and age, type of preschool, mother's age, mother's schooling and household income. The majority of families had less than six residents in the home (84.4\%). The child examined was the youngest in the family in $41.6 \%$ of cases.

The main oral health problems were caries (66.3\%), malocclusion (63.3\%) and TDI (34.2\%) (Table 1). A total of $66.5 \%$ of parents/guardians reported that their child's oral health was good. The prevalence of negative impact on OHRQoL was $32.1 \%$ and $26.2 \%$ among the children and families, respectively.

Table 2 displays the independent variables significantly associated with parental perception of general health in bivariate model. After the adjustments in the multiple logistic regression, the interaction between history of toothache and dental caries $(\mathrm{OR}=10.02 ; 95 \% \mathrm{Cl}: 1.17-$ 85.61), child aged five years ( $\mathrm{OR}=7.40 ; 95 \% \mathrm{Cl}: 1.49-36.63)$, parental perception of general health as poor $(\mathrm{OR}=18.25$; 95\% Cl: 3.36-98.96) and impact on family's OHROoL $(\mathrm{OR}=13.82$; $95 \% \mathrm{Cl}: 4.27-44.72)$ remained significantly associated with parental perception of general health in the final model (Table 3 ).

\section{Discussion}

In the present study, $66.5 \%$ of the parents/guardians considered their child's oral health to be good. This finding is in line with data described in previous surveys (61.6\% to $79.0 \%)(6,7,9,21)$. Studies involving preschool children demonstrate a greater frequency of parental perceptions of poor oral health as children grow older, which is likely due to the cumulative nature of oral health problems $(7,9,21)$.

The prevalence of caries was high. This finding was expected, as the ICDAS II detects the initial stages of tooth decay. Previous studies employing a similar methodology report higher prevalence rates $(95.6 \%$ to $100.0 \%)(1,2)$, suggesting a possible underestimation of caries in the present study, as it was not possible to diagnose conditions classified as code 1. However, the studies cited involved samples from underprivileged areas, differing from the representative sample used in the present study. The prevalence of TDI was $34.2 \%$, which is similar to rates reported in previous studies $(3,4)$. Moreover, the prevalence of malocclusion was high (63.3\%), but within the range reported in the literature $(36.4 \%$ to $74.7 \%)(5,20)$. It is important to stress that prevalence rates of oral health problems can vary across countries/regions and divergences may be explained by the different age groups analyzed and diagnostic criteria employed.

Parental perceptions of children's general health were associated with perceptions of children's oral health status, as these factors are interrelated (22). This finding demonstrates that parents/guardians make this same

Table 1. Frequency distribution of preschool children according to parental perception of oral health, oral health problems determined by clinical diagnosis and impact on quality of life (B-ECOHIS)

\begin{tabular}{|c|c|c|}
\hline \multirow{2}{*}{ Variable } & \multicolumn{2}{|c|}{ Frequency } \\
\hline & $\mathrm{n}$ & $(\%)$ \\
\hline \multicolumn{3}{|c|}{ Perception of oral health } \\
\hline Good & 560 & 66.5 \\
\hline Poor & 282 & 33.5 \\
\hline \multicolumn{3}{|c|}{ Dental caries } \\
\hline Absent & 284 & 33.7 \\
\hline Present & 559 & 66.3 \\
\hline \multicolumn{3}{|l|}{ TDI } \\
\hline Absent & 532 & 65.8 \\
\hline Present & 276 & 34.2 \\
\hline \multicolumn{3}{|c|}{ Malocclusion } \\
\hline Absent & 308 & 36.7 \\
\hline Present & 531 & 63.3 \\
\hline \multicolumn{3}{|c|}{ Impact on child's quality of life } \\
\hline Absent & 572 & 67.9 \\
\hline Present & 271 & 32.1 \\
\hline \multicolumn{3}{|c|}{ Impact on family's quality of life } \\
\hline Absent & 622 & 73.8 \\
\hline Present & 221 & 26.2 \\
\hline Total & 843 & 100.0 \\
\hline
\end{tabular}


Table 2. Bivariate logistic regression for complex samples regarding parental perception of oral health and independent variables among children aged 3 to 5 years

\begin{tabular}{|c|c|c|c|c|}
\hline \multirow{2}{*}{ Variable } & \multicolumn{2}{|c|}{ Perception of oral health } & \multirow{2}{*}{$\mathrm{p}$-value } & \multirow{2}{*}{$\begin{array}{l}\text { Bivariate unadjusted } \\
\text { OR }(95 \% \mathrm{Cl})\end{array}$} \\
\hline & Good n(\%) & Poor n(\%) & & \\
\hline \multicolumn{5}{|l|}{ Sex } \\
\hline Male & $278(63.8)$ & $158(36.2)$ & 0.122 & $1.31(0.92-1.86)$ \\
\hline Female & $282(69.5)$ & $124(30.5)$ & & 1.00 \\
\hline \multicolumn{5}{|l|}{ Age of child } \\
\hline 3 years & 202(73.5) & $73(26.5)$ & & 1.00 \\
\hline 4 years & $218(65.5)$ & $115(34.5)$ & 0.042 & $1.43(0.94-2.17)$ \\
\hline 5 years & $140(59.8)$ & $94(40.2)$ & 0.089 & $1.62(1.01-2.59)$ \\
\hline \multicolumn{5}{|c|}{ Perception of general health } \\
\hline Good & 498(73.3) & $181(26.7)$ & & 1.00 \\
\hline Poor & $60(37.7)$ & $99(62.3)$ & $<0.001$ & $5.30(3.54-7.95)$ \\
\hline \multicolumn{5}{|l|}{ Mother's schooling } \\
\hline$\leq 8$ years of study & $216(55.7)$ & $172(44.3)$ & $<0.001$ & $2.59(1.81-3.71)$ \\
\hline$>8$ years of study & $343(76.1)$ & 108(23.9) & & 1.00 \\
\hline \multicolumn{5}{|c|}{ Monthly household income } \\
\hline$\leq 1$ minimum salary & $252(57.0)$ & 190(43.0) & $<0.001$ & $2.39(1.62-3.52)$ \\
\hline$>1$ minimum salary & $279(77.1)$ & $83(22.9)$ & & 1.00 \\
\hline \multicolumn{5}{|l|}{ Age of parent/guardian } \\
\hline$\leq 30$ years & $265(62.9)$ & $156(37.1)$ & 0.070 & $1.39(0.97-1.99)$ \\
\hline$>30$ years & $283(70.2)$ & $120(29.8)$ & & 1.00 \\
\hline \multicolumn{5}{|c|}{ Number of residents in home } \\
\hline$<6$ & $479(68.6)$ & $219(31.4)$ & & 1.00 \\
\hline$\geq 6$ & $72(55.8)$ & $57(44.2)$ & 0.033 & $1.60(1.03-2.46)$ \\
\hline \multicolumn{5}{|l|}{ Relationship to siblings } \\
\hline Only child & 195(74.1) & $68(25.9)$ & & 1.00 \\
\hline Youngest child & 223(63.9) & $126(36.1)$ & 0.012 & $1.71(1.12-2.63)$ \\
\hline Oldest child & 83(68.0) & $39(32.0)$ & 0.127 & $1.55(0.88-2.75)$ \\
\hline Middle child & $58(55.8)$ & $46(44.2)$ & 0.008 & $2.11(1.22-3.67)$ \\
\hline \multicolumn{5}{|l|}{ Toothache } \\
\hline Yes & $28(35.4)$ & $51(64.6)$ & $<0.001$ & $14.82(6.93-31.70)$ \\
\hline No & $110(86.6)$ & $17(13.4)$ & & 1.00 \\
\hline \multicolumn{5}{|l|}{ Dental caries (general) } \\
\hline Absent & $241(84.9)$ & $43(15.1)$ & & 1.00 \\
\hline Present & $319(57.2)$ & $239(42.8)$ & $<0.001$ & $4.62(2.94-7.24)$ \\
\hline \multicolumn{5}{|c|}{ Dental caries on maxillary incisors } \\
\hline Absent & $402(76.0)$ & $127(24.0)$ & & 1.00 \\
\hline Present & $158(50.5)$ & $155(49.5)$ & $<0.001$ & $3.54(2.48-5.05)$ \\
\hline \multicolumn{5}{|l|}{ Malocclusion } \\
\hline Absent & $212(68.8)$ & $96(31.2)$ & & 1.00 \\
\hline Present & $346(65.3)$ & $184(34.7)$ & 0.997 & $1.00(0.69-1.44)$ \\
\hline \multicolumn{5}{|l|}{ TDI } \\
\hline Absent & $351(66.0)$ & $181(34.0)$ & 0.950 & $1.01(0.67-1.51)$ \\
\hline Present & 195(70.9) & $80(29.1)$ & & 1.00 \\
\hline \multicolumn{5}{|c|}{ Impact on child's quality of life } \\
\hline No & $440(77.1)$ & $131(22.9)$ & & 1.00 \\
\hline Yes & $120(44.3)$ & $151(55.7)$ & $<0.001$ & $4.40(3.00-6.45)$ \\
\hline \multicolumn{5}{|c|}{ Impact on family's quality of life } \\
\hline No & $472(76.0)$ & $149(24.0)$ & & 1.00 \\
\hline Yes & 88(39.8) & $133(60.2)$ & $<0.001$ & $4.94(3.29-7.41)$ \\
\hline
\end{tabular}


association in their children and underscores the importance of carrying out oral health actions in an integral fashion with general health (7).

The association between dental caries and parental perceptions of oral health has been reported in the literature $(6,7,10)$. The present study reports a different outcome: the interaction factor of history of toothache and caries was significantly associated with parents' perceptions of poor oral health in their children. This means that parents/ guardians judged their child's oral health as poor only when dental caries involved toothache. Caries without toothache, toothache without caries or the absence of both conditions were not associated with parents'/guardians' perceptions of oral health. Toothache is one of the main reasons for seeking dental treatment in this age group (8), as parents/ guardians generally only perceive an adverse oral condition when it becomes evident or when pain is involved (23). However, the present study demonstrates that toothache without caries was not associated with parents'/guardians' perceptions of oral health. Toothache not related to caries may be due dental trauma, but TDI was not associated with parents'/guardians' perceptions of their child's oral health. Dental caries is the most predominant adverse oral condition in childhood and is considered to be a primary marker of oral health. However, if parents/guardians do not perceive their child's oral health as poor when dental caries is present without pain, many children will not benefit from dental treatment. The interaction found only for dental caries and toothache may be explained by the involvement of pain or discomfort and difficulty eating, which may reflect parental perceptions regarding oral health $(6,7)$. Moreover, problems related to esthetics, such as malocclusion and caries on the maxillary incisors, were not perceived by parents/guardians as poor oral health.

Child's age of five years was also a predictor of parental perceptions of their child's oral health as poor. Studies involving preschool children have demonstrated a relationship between an older age of children and a worse perception of the oral health of these children on the part of parents/guardians, likely due to the cumulative effect and severity of oral health problems with the increase in age $(7,9,21)$.

A negative impact on the OHROoL of the family was associated with parental perceptions of the oral health of their children. This means that parents/guardians perceived their child's oral health as poor when it caused family distress or financial problems and parents/guardians had to miss days of work to take their children for dental treatment $(11,12)$. Parents/guardians feel responsible for their children's oral health and often express feelings of guilt and/or anger when their children exhibit oral health problems (24).

The present study has the limitations inherent to the cross-sectional design and the answers on the questionnaires may have been subject to information bias. However, a number of measures were taken to diminish the occurrence of such bias, such as the use of a validated questionnaire and the execution of a pilot study. Moreover, some outcomes had a large confidence interval in the multiple logistic regression, which may be a limitation of the study. The broad confidence intervals may have been due to the heterogeneity of the sample (25). However, there may be enough precision to make decisions regarding the usefulness of an intervention. Thus, the present findings suggest that parental perceptions of their child's oral health are influenced by dental caries with pain, an older age of the child, parents'/ guardians' perceptions of the child's general health as poor and the impact on the OHROoL of the family. Studies addressing predictors of 
parental perceptions of children's oral health are important to the planning of public policies aimed at reducing the frequency of oral health problems in preschool children.

\section{Resumo}

0 objetivo do presente estudo foi avaliar a percepção dos pais sobre saúde bucal de pré-escolares. Um estudo transversal foi realizado com 843 crianças brasileiras entre três e cinco anos de idade. Os pais/responsáveis responderam a um questionário autoaplicável sobre a saúde de seus filhos e dados sociodemográficos. Percepções dos pais sobre a saúde bucal de seus filhos foram determinados pela resposta à seguinte pergunta: "Como você descreveria a saúde bucal do seu filho?" A versão brasileira da Early Childhood Oral Health Impact Scale (B-ECOHIS) foi respondido por pais/responsáveis e usada para medir o impacto da qualidade de vida relacionada à saúde bucal $(\mathrm{OHRO} \mathrm{L})$ em crianças pré-escolares e suas familias. Três examinadores realizaram exames bucais nas crianças $(K=0,85-0,90)$. Análise descritiva foi realizada, seguida de uma análise de regressão logística para amostras complexas $(\alpha=5 \%)$. As seguintes variáveis foram significativamente associados com a percepção dos pais sobre saúde bucal dos filhos: percepção ruim dos pais sobre a saúde geral (OR=18,25; IC 95\%: 3,36-98,96), impacto negativo sobre OHROoL da familia (OR=13,82; IC 95\%: 4,27-44,72), crianças com idade de cinco anos (OR=7,40; IC 95\%: 1,49-36,63) e a interação entre o histórico da dor de dente e cárie dentária (OR=10,02; IC 95\%: 1,17-85,61). Percepções parentais de saúde bucal são influenciados pelo impacto sobre OHRQoL da família, a percepção ruim dos pais sobre a saúde geral do seu filho, e as condições clínicas com sintomas, tais como cárie dentária com dor de dente. Outros problemas bucais, tais como má oclusão ou traumatismo dentário, não foram associados com a percepção dos pais sobre saúde $\vec{\nabla}$ bucal de seus filhos.

\section{Acknowledgments}

This study was supported by the State University of Paraiba, the Brazilian

$\Sigma$ Coordination of Higher Education, Ministry of Education (CAPES), the Research Foundation of the State of Minas Gerais (FAPEMIG) and the National Council for Scientific and Technological Development (CNPQ), Brazil.

\section{References}

1. Amorim RG, Figueiredo MJ, Leal SC, Mulder J, Frencken JE. Caries experience in a child population in a deprived area of Brazil, using ICDAS II. Clin Oral Investig 2012;16:513-520.

2. Cook SL, Martinez-Mier EA, Dean JA, Weddell JA, Sanders BJ, Eggertsson $\mathrm{H}$, et al.. Dental caries experience and association to risk indicators of remote rural populations. Int J Paediatr Dent 2008;18:275-283.

3. Feldens $C A$, Kramer PF, Ferreira SH, Spiguel MH, Marquezan M. Exploring factors associated with traumatic dental injuries in preschool children: a Poisson regression analysis. Dent Traumatol 2010;26:143148.

4. Granville-Garcia AF, Menezes VA, Lira PI. Dental trauma and associated factors in Brazilian preschoolers. Dent Traumatol 2006;22:318-322.

5. Carvalho AC, Paiva SM, Scarpelli AC, Viegas CM, Ferreira FM, Pordeus IA. Prevalence of malocclusion in primary dentition in a populationbased sample of Brazilian preschool children. Eur J Paediatr Dent 2011;12:107-111.

6. Sohn W, Taichman LS, Ismail Al, Reisine S. Caregiver's perception of child's oral health status among low income African Americans. Pediatr Dent 2008;30:480-487.

7. Talekar BS, Rozier RG, Slade GD, Ennett ST. Parental perceptions of their preschool-aged children's oral health. J Am Dent Assoc 2005;136:364372 .
8. Camargo MBJ, Barros AJD, Frazão P, Matijasevich A, Santos IS, Peres $M A$, et al.. Predictors of dental visits for routine check-ups and for the resolution of problems among preschool children. Rev Saude Publica 2012;46:87-97.

9. Wandera M, Kayondo J, Engebretsen IM, Okullo I, Astrom AN. Factors associated with caregivers' perception of children's health and oral health status: a study of 6- to 36-month-olds in Uganda. Int J Paediatr Dent 2009;19:251-262.

10. Piovesan C, Marquezan M, Kramer PF, Bönecker M, Ardenghi TM. Socioeconomic and clinical factors associated with caregivers' perceptions of children's oral health in Brazil. Community Dent Oral Epidemiol 2011;39:260-267.

11. Gomes MC, Pinto-Sarmento TC, Costa EM, Martins CC, Granville-Garcia $A F$, Paiva SM. Impact of oral health conditions on the quality of life of preschool children and their families: a cross-sectional study. Health Qual Life Outcomes 2014;12:55.

12. Scarpelli AC, Paiva SM, Viegas CM, Carvalho AC, Ferreira FM, Pordeus IA. Oral health-related quality of life among Brazilian preschool children. Community Dent Oral Epidemiol 2013;41:336-344.

13. Brazilian Institute of Geography and Statistics. First Results of the 2010 Census. Available at: "http://www.censo2010.ibge.gov.br/ dadosdivulgados/index.php?uf=25". Accessed Aug 3, 2012.

14. Browner WS, Newman TB, Hulley SB. Estimating sample size and power: applications and exemples. In: Hulley SB, Cummings SR, Browner WS, et al. Designing clinical research. 3rd ed. Philadelphia: Lippincott and Williams \& Wilkins; 2007. p 65-94.

15. Altman DG. Practical statistics for medical research. 2nd ed. London: Chapman and Hall; 2006.

16. Tesch FC, Oliveira BH, Leão A. Semantic equivalence of the Brazilian version of the Early Chilhood Oral Health Impact Scale. Cad Saude Publica 2008;24:1897-1909.

17. Ismail Al, Sohn W, Tellez M, Amaya A, Sen A, Hasson H. The International Caries Detection and Assessment System (ICDAS): an Integrated System for Measuring Dental Caries. Community Dent Oral Epidemiol 2007;35:170-178.

18. Andreasen JO, Andreasen FM, Andersson L. Textbook and color atlas of traumatic injuries to the teeth. 4th ed. Oxford: Blackwell; 2007.

19. Foster TD, Hamilton MC. Occlusion in the primary dentition. Study of children at 21 to 3 years of age. Br Dent J 1969;126:76-79.

20. Grabowski R, Stahl F, Gaebel M, Kundt G. Relationship between occlusal findings and orofacial myofunctional status in primary and mixed dentition. Part I: Prevalence of malocclusions. J Orofac Orthop 2007;68:26-37.

21. Braun $P A$, Lind $K E$, Batliner $T$, Brega $A G$, Henderson $W G$, Nadeau $K$ et al.. Caregiver reported oral health-related quality of life in young American Indian children. J Immigr Minor Health 2014;16:951-958.

22. Petersen PE. The World Oral Health Report 2003: continuous improvement of oral health in the 21st century - the approach of the WHO Global Oral Health Programme. Community Dent Oral Epidemiol 2003;31:3-23

23. Lee GHM, McGrath C, Yiu CKY, King NM. A comparison of a generic and oral health-specific measure in assessing the impact of early childhood caries on quality of life. Community Dent Oral Epidemiol 2010;38:333339.

24. Arora A, Bedros D, Bhole S, Do LG, Scott J, Blinkhorn A, et al.. Child and family health nurses' experiences of oral health of preschool children: a qualitative approach. J Public Health Dent 2012;72:149-155.

25. Higgins JPT, Green S. Cochrane Handbook for Systematic Reviews of Interventions Version 5.1.0 [updated March 2011]. The Cochrane Collaboration. 2011; Available from www.cochrane-handbook.org. Accessed: 18 November 2014. 